\title{
Paradoxical stimulation of human sperm motility by 2-deoxyadenosine
}

\author{
R. J. Aitken, A. Mattei and S. Irvine \\ $M R C$ Unit of Reproductive Biology, 37 Chalmers Street, Edinburgh EH3 9EW, U.K.
}

\begin{abstract}
Summary. Exposure of cryostored human spermatozoa to 2-deoxyadenosine resulted in significant increases in percentage motility, the linear velocity of progression and the frequency of sperm head rotation, which were maximal at a dose of $2.5 \mathrm{~mm}$. At the same dose both adenosine and caffeine significantly increased percentage motility, although neither compound influenced the quality of sperm movement as assessed by time-exposure photomicrography. 2-Deoxyadenosine was also significantly more effective than caffeine in sustaining the motility of cryostored spermatozoa as well as in enhancing the motility of fresh and washed preparations of human spermatozoa.

The ability of caffeine and 2-deoxyadenosine to influence sperm motility was counteracted by the presence of calcium in the external medium although the latter was less susceptible to such inhibition and still enhanced motility in the presence of calcium levels $(1.7 \mathrm{~mm})$ typical of media used for in-vitro fertilization.

The mechanism of action of 2-deoxyadenosine was associated with an increase of intracellular cAMP levels, which were sustained over a time course lasting from 5 to $180 \mathrm{~min}$ and exhibited significant dose dependency over the range $1-10 \mathrm{~mm}$. The response to 2-deoxyadenosine did not involve any changes in the steady state levels of ATP and was augmented by the presence of the phosphodiesterase inhibitors, IBMX and caffeine.

We conclude that 2-deoxyadenosine is a powerful stimulator of human sperm motility and that this effect involves an increase of intracellular cAMP levels via mechanisms which do not involve the classical ' $R$ '-site receptor mediated pathway.
\end{abstract}

\section{Introduction}

Cyclic adenosine $3^{\prime}, 5^{\prime}$-monophosphate (cAMP) is thought to be an important component of the biochemical mechanisms involved in the control of sperm function, with respect to the regulation of motility (Hoskins et al., 1975; Garbers \& Kopf, 1980; Tash \& Means, 1983; Pariset et al., 1983; Pariset et al., 1985) and the ability to fertilize (Fraser, 1979, 1981). Most experimental evidence suggesting a role for cAMP in the control of these processes has come from studies in which phosphodiesterase inhibitors have been shown to elevate cAMP and simultaneously enhance sperm motility (Vijayaraghavan et al., 1985) and fertilizing potential (Fraser, 1979, 1981; Stein \& Fraser, 1984). The fact that the phosphodiesterase inhibitor, caffeine, is capable of producing these effects with human spermatozoa (Aitken et al., 1983) has stimulated clinical interest in the use of reagents that increase intracellular cAMP in the treatment of infertility associated with the impairment of sperm motility and/or fertilizing potential, such as astheno- or oligozoospermia.

Adenosine is known to be involved in the physiological regulation of adenylate cyclase, inhibiting or stimulating the activity of this enzyme depending on the cell-type in question (Londos \& Wolff, 1977). The influence of adenosine is mediated via 2 classes of binding site, ' $R$ ' and ' $P$ ', the activity of which depends upon the integrity of an intact ribose or purine ring respectively. In all 
cell types studied to date the activation of adenylate cyclase has been shown to depend upon the presence of R-type receptors on the external surface of the plasma membrane. In the course of an investigation into the role of adenosine in the regulation of adenylate cyclase activity in human spermatozoa, we found that 2-deoxyadenosine, an analogue of adenosine with a modified ribose ring, paradoxically stimulates the production of cAMP by these cells. In this study we have examined the effects of deoxyadenosine on the cyclic AMP content and motility of human spermatozoa comparing the results with those achieved after addition of caffeine, which is currently regarded as the most potent (Makler et al., 1980) and hence the most clinically useful (Barkay et al., 1984), reagent available for artificially stimulating human sperm function. Cryostored human spermatozoa were used because cryostorage is known to reduce the motility of human spermatozoa and this inhibition is reversible upon addition of reagents, like caffeine, that raise the intracellular level of cAMP (Aitken et al., 1983).

\section{Materials and Methods}

Spermatozoa. Semen samples from normospermic males $\left(>20 \times 10^{6}\right.$ spermatozoa $/ \mathrm{ml},>40 \%$ motility, $>40 \%$ normal morphology) were produced by masturbation and cryostored using the techniques described by Jackson \& Richardson (1977). The cryoprotective medium contained glycerol $(15 \% \mathrm{v} / \mathrm{v})$, egg yolk $(28 \% \mathrm{v} / \mathrm{v})$, fructose $(1 \cdot 24 \% \mathrm{w} / \mathrm{v})$ and $56 \%(\mathrm{v} / \mathrm{v})$ of a $3 \cdot 2 \%(\mathrm{w} / \mathrm{v})$ stock solution of sodium citrate in 3-times distilled water. This medium was gradually added in $0 \cdot 5-\mathrm{ml}$ amounts to the semen sample at room temperature until a 1:1 dilution was achieved. The samples were then frozen at an average rate of $7.8^{\circ} \mathrm{C} / \mathrm{min}$ in the vapour phase of a Dewar flask containing liquid nitrogen. After cooling to at least $-120^{\circ} \mathrm{C}$ the samples were rapidly transferred to a numbered and colour-coded location in a sperm storage bank and immersed in liquid nitrogen for at least 20 days before thawing. The cryostored samples were ultimately thawed for $5 \mathrm{~min}$ at room temperature followed by $20 \mathrm{~min}$ at $37^{\circ} \mathrm{C}$. In some instances the spermatozoa were washed free of cryostorage medium and resuspended in Medium BWW (Biggers et al., 1971). This medium normally contained $1.7 \mathrm{mM}-\mathrm{Ca}^{2+}$ but for certain experiments the calcium content of the medium was reduced; then, $\mathrm{NaCl}$ was added to maintain the osmolarity at a constant $310 \mathrm{mosmol} / \mathrm{kg}$.

Movement characteristics. The proportion of motile cells in the individual samples was assessed at $\times 250$ with the aid of an eye-piece graticule. The movement characteristics exhibited by the spermatozoa were measured by time-exposure photomicrography at $37^{\circ} \mathrm{C}$, under dark-field illumination, employing an exposure time of $1 \mathrm{sec}$ (Overstreet et al., 1979; Aitken et al., 1982). Four polaroid prints were taken for each sample and the movement characteristics were assesed on 20 randomly selected tracks. The attributes of sperm motility evaluated included the linear velocity of progression $(\mu \mathrm{m} / \mathrm{sec})$, the amplitude of lateral sperm head displacement $(\mu \mathrm{m})$, the frequency of sperm head rotation (per sec) and the proportion of cells exhibiting a 'rolling' or 'yawing' pattern of progression.

cAMP determination. The spermatozoa were centrifuged at $500 \mathrm{~g}$ for $5 \mathrm{~min}$ after which the supernatant was withdrawn and the cAMP extracted from the pellet with ice-cold ethanol for $20 \mathrm{~min}$. Once the cellular material had been separated by a further centrifugation step ( $2000 \mathrm{~g}$ for $10 \mathrm{~min}$ ) the supernatant was dried under a stream of nitrogen and reconstituted in $500 \mu 10.01 \mathrm{M}$ phosphatebuffered saline (PBS), $\mathrm{pH} 7 \cdot 4$.

Cyclic AMP from the extracted samples was estimated by a radioimmunoassay procedure, based on the method of Steiner et al. (1972) as modified by Harper \& Brooker (1975). Briefly, duplicate acetylated samples and standards ( $0.2 \mathrm{ml}$ of each made up in $0.01 \mathrm{M}-\mathrm{PBS}, \mathrm{pH} 7.4)$ were incubated in the presence of anti-cAMP antiserum (Dr M. Schumaker, Institute für Physiologische Chemie, Hamburg, FRG) $(0.1 \mathrm{ml}$ of $1: 70000$ dilution made up in $0.01 \mathrm{M}-\mathrm{PBS}, \mathrm{pH} 7.4$ and $0.3 \%$ gamma-globulin) and ${ }^{125} \mathrm{I}$-labelled $2^{\prime}, 0$-succinyl cAMP-tyrosine methyl ester tracer 
( 30000 c.p.m.; Sigma Chemical Co., St Louis, MO, U.S.A.) for $16 \mathrm{~h}$ at $4^{\circ} \mathrm{C}$. The bound complexes were precipitated by the addition of $1 \mathrm{ml}$ ice-cold $17 \%$ polyethylene glycol (BDH, Poole, Dorset, U.K.), separated by centrifugation ( $30 \mathrm{~min}$ at $200 \mathrm{~g}$ and $4^{\circ} \mathrm{C}$ ), and counted in a multihead gamma counter (Nuclear Enterprises 1600; Sighthill, Edinburgh, U.K.). The level of cyclic AMP in each sample was calculated by computer, relative to a log-logit standard curve constructed for each assay, and expressed as fmol per $10^{6}$ spermatozoa. The cross-reactivities of the anti-succinyl cAMP antiserum were $100 \%$ for cAMP, $0.0035 \%$ for cGMP, $0.0005 \%$ for AMP, $0.00045 \%$ for ADP, $0.00069 \%$ for ATP, $0.0005 \%$ for GTP and $0.001 \%$ for 2 deoxyadenosine. The intra- and inter-assay coefficients of variation were $6.3 \%$ and $14.5 \%$ respectively.

ATP assay. Extraction of ATP was achieved by mixing $25 \mu$ of the sperm suspension $\left(10^{7} / \mathrm{ml}\right)$ with an equal volume of $0.01 \%$ trichloracetic acid (TCA) followed by the addition of $850 \mu 1$ Tris-EDTA buffer (0.1 M-Tris, 2 mM-EDTA, pH 7-75). Bioluminessence was measured with a Berthold luminometer (Laboratory Impex Ltd, Twickenham, U.K.) after addition of $100 \mu 1$ luciferin-luciferase reagent (LKB-Wallace, Turku, Finland) and the light emission was calibrated using standard solutions of ATP (LKB-Wallace).

Reagents. Adenosine, 2-deoxyadenosine, caffeine and IBMX were all solubilized in the balanced salt solution described by Aitken et al. (1983) containing $94.8 \mathrm{~mm}-\mathrm{NaCl}, 4.9 \mathrm{mM}-\mathrm{KCl}, 1.7 \mathrm{~mm}-$ $\mathrm{CaCl}_{2} .2 \mathrm{H}_{2} \mathrm{O}, 1.2 \mathrm{mM}-\mathrm{KH}_{2} \mathrm{PO}_{4}$ and $1.2 \mathrm{~mm}-\mathrm{MgSO}_{4} .7 \mathrm{H}_{2} \mathrm{O}(\mathrm{pH} .4)$. In certain instances the calcium was omitted and the $\mathrm{NaCl}$ concentration was then increased to $96.5 \mathrm{~mm}$. Control incubations contained the solubilization buffer alone.

Statistics. All statistical comparisons were carried out using non-parametric statistics (the Wilcoxon matched pairs signed ranks and the Mann-Whitney $U$ tests).

\section{Results}

$c A M P$

Comparison of adenosine and 2-deoxyadenosine. Exposure of non-cryostored, washed, human spermatozoa to $2.5 \mathrm{~mm}$-adenosine or 2-deoxyadenosine (the optimal dose for the stimulation of motility as indicated below) for $3 \mathrm{~h}$ resulted in significant changes in the cAMP content of human spermatozoa. Adenosine increased the intracellular level ( \pm s.e.m.) of cAMP from $104 \cdot 6 \pm 14 \cdot 1$ to $206.4 \pm 27.7 \mathrm{fmol} / 10^{6}$ spermatozoa $(P<0.01)$, while exposure of the same samples to 2-deoxyadenosine raised the cAMP level still further to $445.6 \pm 72.4 \mathrm{fmol} / 10^{6}$ spermatozoa $(P<0.01)$ compared to the controls (aliquants of the same sperm populations incubated for $3 \mathrm{~h}$ without drug addition) or adenosine-treated samples.

Comparison of 2-deoxyadenosine with forskolin, IBMX and caffeine. The stimulatory effects obtained with 2-deoxyadenosine were subsequently compared with those achieved with a classical activator of the catalytic subunit of adenylate cyclase, forskolin, and 2 inhibitors of phosphodiesterase, isobutylmethyl xanthine (IBMX) and caffeine. The results of a time-course study indicated that the response to 2-deoxyadenosine was rapid and sustained, being significantly elevated above control values $(P<0.02)$ within $5 \mathrm{~min}$ and thereafter showing no time-dependent changes (Fig. 1$)$. In contrast $10 \mu \mathrm{M}$-forskolin, a dose which is sufficient to activate the adenylate cyclase system present in, for example, turkey erythrocytes (McOsker et al., 1983), had no significant effect on the cAMP content of human spermatozoa at any time investigated. The phosphodiesterase inhibitors also induced a rapid rise in cAMP levels, which were significanly above control values after 5 min of exposure for IBMX $(P<0.05)$ and caffeine $(P<0.05)$ and thereafter tended to show a timedependent fall, although this trend was not statistically significant. At a fixed time point of 


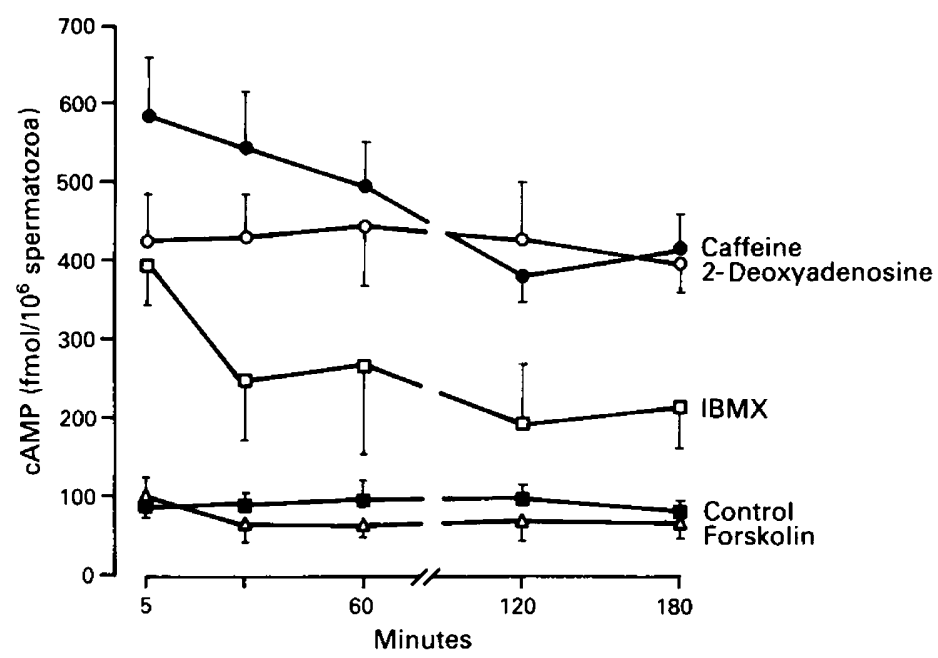

Fig. 1. Time-course analysis of the influence of caffeine ( $2 \mathrm{mM}, 0)$, 2-deoxyadenosine $(2.5 \mathrm{~mm}$, $0), \operatorname{IBMX}(0.2 \mathrm{mM}, \square)$, and forskolin $(10 \mu \mathrm{M}, \triangle)$ on the cAMP content of human spermatozoa ( $n=4$ samples from 4 individuals).

Table 1. Dose-dependency of the cAMP levels recorded for human spermatozoa exposed to 2-deoxyadenosine, caffeine and IBMX for $20 \mathrm{~min}$

\begin{tabular}{lcc}
\hline Compound & $\begin{array}{c}\text { Dose } \\
(\mathrm{mM})\end{array}$ & $\begin{array}{c}\text { cAMP } \\
\text { (fmol/106 spermatozoa) }\end{array}$ \\
\hline 2-deoxyadenosine & 1 & $224 \pm 12^{* *}$ \\
& $2 \cdot 5$ & $352 \pm 47^{*}$ \\
& $5 \cdot 0$ & $520 \pm 42^{*}$ \\
Caffeine & $10 \cdot 0$ & $781 \pm 84^{*}$ \\
& 1 & $287 \pm 48^{* *}$ \\
& $2 \cdot 5$ & $273 \pm 61$ \\
IBMX & $5 \cdot 0$ & $259 \pm 62$ \\
& $10 \cdot 0$ & $386 \pm 68$ \\
& $0 \cdot 2$ & $309 \pm 47^{* *}$ \\
& $0 \cdot 5$ & $386 \pm 59$ \\
Control & $1 \cdot 0$ & $496 \pm 130$ \\
& $2 \cdot 0$ & $597 \pm 93$ \\
& - & $106 \pm 15$ \\
\hline
\end{tabular}

Values are mean \pm s.e.m., for 4 samples from 4 individuals. ${ }^{*} P<0.02, * * P<0.01$ with respect to control or previous doses.

20 min a dose-dependent analysis was performed for the 3 active compounds IBMX, caffeine and 2-deoxyadenosine (Table 1). The intracellular values of cAMP were significantly elevated over control values for all 3 compounds at the lowest doses tested and thereafter exhibited significant dose-dependency with 2-deoxyadenosine, but not with IBMX and caffeine (Table 1). When spermatozoa were exposed for $20 \mathrm{~min}$ to a maximal dose of caffeine $(10 \mathrm{~mm})$ in the presence of 2-deoxyadenosine, the cAMP levels recorded, $819 \cdot 0 \pm 120 \cdot 2 \mathrm{fmol} / 10^{6}$ spermatozoa (mean \pm s.e.m. 
Table 2. Influence of IBMX $(0 \cdot 2 \mathrm{mM})$ on the cAMP content of human spermatozoa exposed to 2-deoxyadenosine ( $2.5 \mathrm{~mm})$ for $3 \mathrm{~h}$

\begin{tabular}{lrrrrr}
\hline & \multicolumn{5}{c}{ cAMP content (fmol/10 } \\
\cline { 2 - 5 } & \multicolumn{5}{c}{ Sample $\dagger$} \\
\cline { 2 - 5 } Treatment & \multicolumn{1}{c}{1} & 2 & 3 & 4 & Mean \pm s.e.m. \\
\hline Control & 73 & 46 & 60 & 23 & $50 \cdot 5 \pm 10 \cdot 7$ \\
2-deoxyadenosine & 347 & 439 & 220 & 101 & $277 \cdot 0 \pm 74 \cdot 0^{* *}$ \\
2-deoxyadenosine+IBMX & 568 & 1323 & 826 & 143 & $715 \cdot 0 \pm 247 \cdot 0^{* *}$ \\
\hline
\end{tabular}

** $P<0.01$ relative to control values.

$\uparrow$ Samples from 4 separate individuals.

Table 3. Influence of 2-deoxyadenosine on the cAMP content of cryostored human spermatozoa $\dagger$

\begin{tabular}{lcc}
\hline & \multicolumn{2}{c}{$\begin{array}{c}\text { Cyclic AMP content } \\
\text { (fmol/106 }\end{array}$} \\
\cline { 2 - 3 } Time (min) & Treated & Control \\
\hline 1 & $283 \cdot 8 \pm 113 \cdot 5^{*}$ & $121 \cdot 0 \pm 35 \cdot 8$ \\
5 & $241 \cdot 8 \pm 49 \cdot 8^{*}$ & $115 \cdot 1 \pm 31 \cdot 4$ \\
30 & $247 \cdot 7 \pm 55 \cdot 5^{* *}$ & $105 \cdot 4 \pm 27 \cdot 4$ \\
60 & $215 \cdot 6 \pm 52 \cdot 8^{*}$ & $92 \cdot 7 \pm 17 \cdot 7$ \\
120 & $241 \cdot 5 \pm 45 \cdot 7^{*}$ & $116 \cdot 7 \pm 26 \cdot 3$ \\
\hline Values are mean \pm s.e.m. for 7 & samples from 7 \\
individuals. \\
$* P<0 \cdot 05, * * P<0 \cdot 01$ relative to control values. \\
$\dagger$ All incubations contain 2 mM-caffeine to inhibit \\
phosphodiesterase activity.
\end{tabular}

$n=6)$, were significantly higher $(P<0.002)$ than the levels observed in the presence of caffeine alone $\left(529.0 \pm 56.5 \mathrm{fmol} / 10^{6}\right.$ spermatozoa). The enhancing effect of a phosphodiesterase inhibitor is also shown in Table 2, in which a $3-\mathrm{h}$ exposure to IBMX is seen to elevate the response to $2 \cdot 5 \mathrm{~mm}$-2-deoxyadenosine.

Influence of 2-deoxyadenosine on cryostored spermatozoa. Since a probable clinical application of stimulatory reagents such as 2-deoxyadenosine is in enhancing the diminished motility of cryostored spermatozoa, an experiment was performed to determine whether this compound was also effective in elevating the cAMP content of such cells. This analysis again took the form of a time-course study, during which phosphodiesterase activity was inhibited by 2 mM-caffeine. The results of this analysis revealed that 2-deoxyadenosine was capable of inducing a significant increase in the cAMP content of the cryostored cells at all time points assessed from 1 to $120 \mathrm{~min}$ (Table 3).

ATP levels. To determine whether 2-deoxyadenosine was inducing an increase in intracellular cAMP through an effect on the availability of ATP the latter was monitored in cells exposed to deoxyadenosine, IBMX, forskolin and caffeine for various periods (Fig. 2) at doses which had previously been shown to give 4-5-fold (caffeine and 2-deoxyadenosine), 2-3-fold (IBMX) or no (forskolin) changes in cAMP over an identical time course (Fig. 1). The results did not reveal any differences in the influence of these groups of compounds on the ATP content of human 


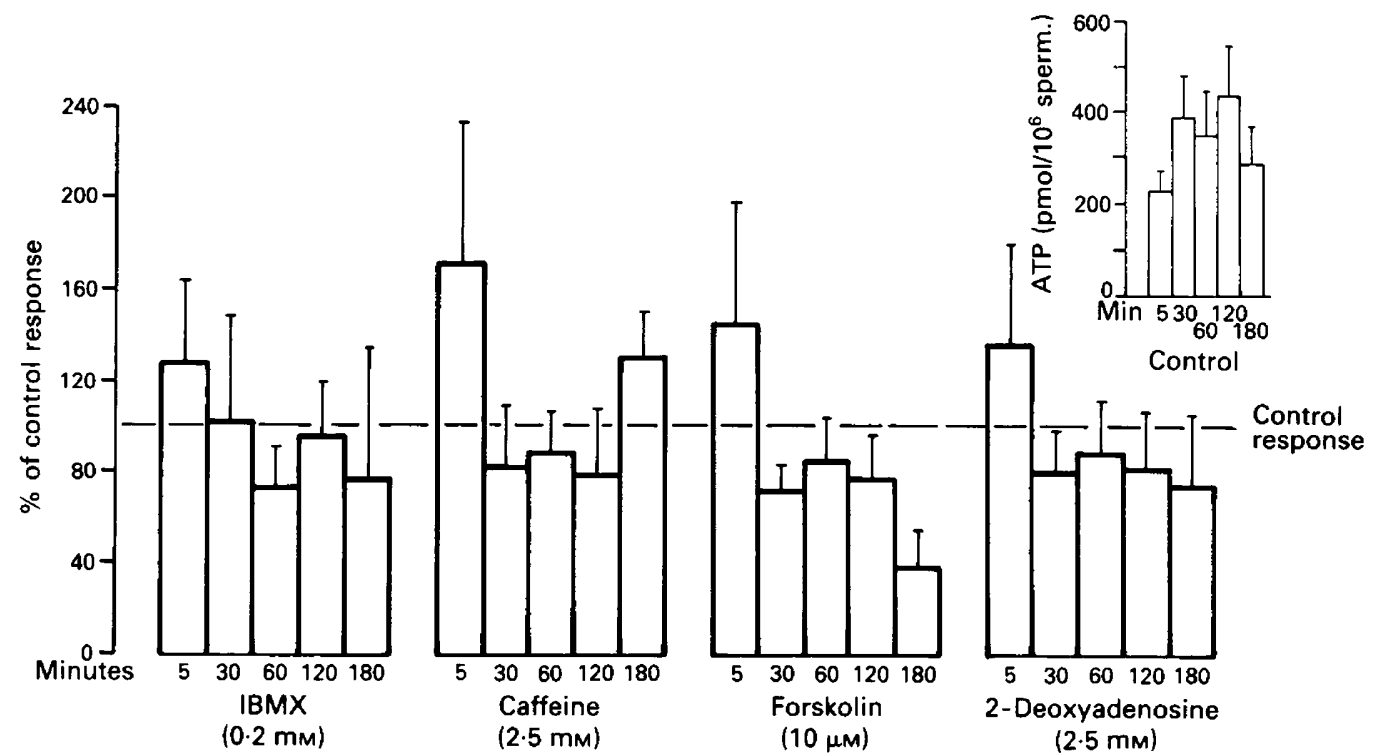

Fig. 2. Time-course analysis of the influence of IBMX, caffeine, forskolin and 2-deoxyadenosine on the ATP content of human spermatozoa. Inset indicates the actual ATP levels recorded in the control incubations ( $n=6$ samples from 6 individuals).

spermatozoa with the exception of forskolin which was associated with a significant fall in ATP levels after incubation for $3 \mathrm{~h}(P<0.05)$.

Influence of $A 23187$. The possibility was also investigated that 2-deoxyadenosine might be active by perturbing the plasma membrane, thereby allowing the influx of calcium, a cation which has been shown to enhance sperm adenylate cyclase activity in several species (Hyne \& Garbers, 1979; Kopf \& Vacquier, 1985). In this study human spermatozoa were incubated with $0.2 \mathrm{mM}$-IBMX for 1,5 or $15 \mathrm{~min}$ with or without the ionophore $\mathrm{A} 23187$, prepared as an aqueous suspension $(0.05 \mathrm{mg} / \mathrm{ml})$ as described by Aitken et al. (1984). This reagent is capable both of perturbing biological membranes (Klausner et al., 1979) and inducing the influx of calcium. The mean \pm s.e.m. levels of cAMP recorded at 1,5 and $15 \mathrm{~min}$ were, respectively, $513.3 \pm 77 \cdot 3,459 \cdot 7 \pm 115.4$ and $471.0 \pm$ $96.0 \mathrm{fmol} / 10^{6}$ spermatozoa for IBMX and 521.0 $\pm 67 \cdot 6,599 \cdot 7 \pm 78 \cdot 0$ and $576 \cdot 0 \pm 75 \cdot 2 \mathrm{fmol} / 10^{6}$ spermatozoa for IBMX plus A23187. These levels were significantly higher than the control values of $154.0 \pm 6 \cdot 7,146.7 \pm 19.9$ and $126.0 \pm 16.4 \mathrm{fmol} / 10^{6}$ spermatozoa $(P<0.05)$ but not significantly different from each other.

\section{Movement characteristics}

Comparison of 2-deoxyadenosine and caffeine. To assess whether these changes in intracellular cAMP content significantly influenced the movement characteristics of cryostored human spermatozoa, dose-dependent studies were performed for caffeine and 2-deoxyadenosine. The proportion of motile cells was significantly increased by 2-deoxyadenosine at 1 and $2.5 \mathrm{~mm}$, the largest increase being observed at $2.5 \mathrm{~mm}$ which induced a $30.0 \pm 8.9 \%$ increase in the percentage of motile cells (Table 4). This increase in motility was associated with significant changes in the movement characteristics of the spermatozoa particularly with respect to the linear velocity of progression which increased from $32.9 \pm 0.6 \mu \mathrm{m} / \mathrm{sec}$ in the controls to a maximum of $40.9 \pm 1.7 \mu \mathrm{m} / \mathrm{sec}$ at the $2.5 \mathrm{~mm}$ dose, equivalent to a $25 \cdot 0 \pm 6 \cdot 4 \%$ increase in velocity over control levels. Significant increases were 
Table 4. Dose-dependent study of the changes in human sperm motility exhibited by cryostored samples exposed to 2-deoxyadenosine or caffeine for $20 \mathrm{~min}$

\begin{tabular}{|c|c|c|c|c|}
\hline $\begin{array}{l}\text { Movement } \\
\text { characteristic }\end{array}$ & Control & $1.0 \mathrm{~mm}$ & $2.5 \mathrm{~mm}$ & $5.0 \mathrm{~mm}$ \\
\hline \multicolumn{5}{|l|}{ 2-Deoxyadenosine } \\
\hline Motility (\%) & $43 \cdot 6 \pm 5 \cdot 2$ & $50 \cdot 9 \pm 3 \cdot 4^{*}$ & $56 \cdot 1 \pm 6 \cdot 9^{* *}$ & $47 \cdot 2 \pm 5 \cdot 3$ \\
\hline Velocity $(\mu \mathrm{m} / \mathrm{sec})$ & $32.9 \pm 0.6$ & $38 \cdot 2 \pm 0.8^{* *}$ & $40 \cdot 9 \pm 1 \cdot 7^{* *}$ & $37.2 \pm 1.0^{* *}$ \\
\hline Frequency of & & & & \\
\hline rotation $(/ \mathrm{sec})$ & $5 \cdot 5 \pm 0.4$ & $7 \cdot 1 \pm 0 \cdot 3^{* *}$ & $7 \cdot 3 \pm 0 \cdot 5^{* *}$ & $6 \cdot 7 \pm 0 \cdot 3^{*}$ \\
\hline $\begin{array}{l}\text { Amplitude of } \\
\text { displacement }(\mu \mathrm{m})\end{array}$ & $6.9 \pm 0.2$ & $7 \cdot 1 \pm 0 \cdot 2$ & $7 \cdot 0 \pm 0 \cdot 1$ & $7.0 \pm 0.2$ \\
\hline Rolling $(\%)$ & $82 \cdot 7 \pm 2 \cdot 5$ & $90.0 \pm 1.6^{*}$ & $90 \cdot 0 \pm 1 \cdot 1^{*}$ & $86.7 \pm 2 \cdot 2^{*}$ \\
\hline \multicolumn{5}{|l|}{ Caffeine } \\
\hline Motility (\%) & $48 \cdot 0 \pm 4 \cdot 4$ & $53 \cdot 7 \pm 4 \cdot 1^{* *}$ & $57 \cdot 0 \pm 5 \cdot 2^{* *}$ & $57 \cdot 1 \pm 6 \cdot 0^{*}$ \\
\hline Velocity $(\mu \mathrm{m} / \mathrm{sec})$ & $35.4 \pm 0.8$ & $34 \cdot 7 \pm 0.9$ & $34.6 \pm 0.8$ & $33.1 \pm 0.7$ \\
\hline $\begin{array}{l}\text { Frequency of } \\
\text { rotation }(/ \mathrm{sec})\end{array}$ & $7 \cdot 2 \pm 0.4$ & $7 \cdot 3 \pm 0 \cdot 3$ & $7 \cdot 2 \pm 0 \cdot 2$ & $6.8 \pm 0.2$ \\
\hline $\begin{array}{l}\text { Amplitude of } \\
\text { displacement }(\mu \mathrm{m})\end{array}$ & $7 \cdot 6 \pm 0 \cdot 1$ & $7 \cdot 7 \pm 0 \cdot 1$ & $7 \cdot 8 \pm 0 \cdot 2$ & $8 \cdot 1 \pm 0 \cdot 4$ \\
\hline
\end{tabular}

Values are mean \pm s.e.m. for 9 samples from 9 individuals.

${ }^{*} P<0.05,{ }^{* *} P<0.01$.

also observed at all doses tested in the frequency of sperm-head rotation, although the maximum degree of change was again recorded at the $2.5 \mathrm{~mm}$ dose (Table 4). In contrast, the amplitude of lateral sperm-head displacement was not significantly altered from the control value of $6.9 \pm 0.2 \mu \mathrm{m}$ after exposure to 2 -deoxyadenosine. With respect to the pattern of sperm movement, a majority of these cryostored spermatozoa $(82.7 \pm 2.5 \%)$ exhibited a 'rolling' swimming motion, the incidence of which showed a slight but statistically significant increase at all doses tested (Table 4).

An equivalent dose-response analysis for caffeine also revealed a significant change in the proportion of motile cells, which was statistically significant at all doses examined giving, at the $2.5 \mathrm{~mm}$ dose, a $20.4 \pm 8.2 \%$ increase in motility over the control value (Table 4). However, in contrast to 2-deoxyadenosine, none of the other movement characteristics exhibited by these cryostored spermatozoa was statistically influenced by the presence of caffeine. Indeed, in 6 out of the 9 samples tested, sperm velocity was reduced by exposure to caffeine giving, overall, a net $16 \cdot 0 \pm 12 \cdot 3 \%$ reduction in the linear velocity of progression over control values.

Caffeine and 2-deoxyadenosine were further compared for their ability to sustain an increase in the motility of cryostored cells after a temporary period of exposure to these reagents. In this study cryostored spermatozoa were incubated in the presence of $2.5 \mathrm{~mm}$ 2-deoxyadenosine or $2.5 \mathrm{~mm}$ caffeine for $20 \mathrm{~min}$ before centrifugation and resuspension in unsupplemented Medium BWW; the motility of the spermatozoa was then assessed at 30,60,120 and $180 \mathrm{~min}$ (Table 5). In the presence of 2-deoxyadenosine, sperm motility was significantly elevated above control values at all times tested, so that even $3 \mathrm{~h}$ after withdrawal of this compound the percentage of motile cells was still significantly elevated relative to the controls. In contrast, the spermatozoa incubated in the presence of caffeine exhibited a significantly enhanced degree of motility for the first hour but then returned to control levels (Table 5).

Comparison of adenosine and 2-deoxyadenosine. Since adenosine as well as deoxyadenosine was able to increase the intracellular levels of cAMP in human spermatozoa these compounds were compared directly for their relative abilities to influence the motility of cryostored spermatozoa. In this study (Table 6) 2-deoxyadenosine significantly increased the percentage of motile cells, their 
Table 5. Percentage motility of cryostored human spermatozoa at various times after a $20 \mathrm{~min}$ exposure to $2.5 \mathrm{~mm}$-deoxyadenosine or 2.5 mM-caffeine

\begin{tabular}{lccc}
\hline $\begin{array}{l}\text { Time after } \\
\text { withdrawal of } \\
\text { compound (min) }\end{array}$ & Control & 2-Deoxyadenosine & Caffeine \\
\cline { 2 - 4 } & $44 \cdot 4 \pm 2 \cdot 3$ & $54 \cdot 1 \pm 1 \cdot 5^{*}$ & $51 \cdot 7 \pm 1 \cdot 6^{*}$ \\
\hline 30 & $42 \cdot 2 \pm 2 \cdot 6$ & $50 \cdot 2 \pm 2 \cdot 4^{*}$ & $47 \cdot 0 \pm 2 \cdot 4^{*}$ \\
60 & $42 \cdot 2 \pm 3 \cdot 2$ & $49 \cdot 9 \pm 3 \cdot 4^{*}$ & $43 \cdot 2 \pm 2 \cdot 5$ \\
120 & $39 \cdot 5 \pm 4 \cdot 1$ & $46 \cdot 6 \pm 3 \cdot 8^{*}$ & $39 \cdot 5 \pm 3 \cdot 5$ \\
180 & & \\
\hline
\end{tabular}

Values are mean \pm s.e.m. for 8 samples from 8 individuals.

${ }^{*} P<0.05$.

Table 6. Comparative study of the influence of equivalent concentrations $(2.5 \mathrm{~mm})$ of adenosine and 2-deoxyadenosine on the movement characteristics of cryostored human spermatozoa after a 20 -min incubation period

\begin{tabular}{lccc}
\hline \multirow{2}{*}{$\begin{array}{l}\text { Movement } \\
\text { characteristics }\end{array}$} & Control & Adenosine & 2-Deoxyadenosine \\
\cline { 2 - 4 } & $40 \cdot 0 \pm 2 \cdot 3$ & $44 \cdot 9 \pm 2 \cdot 5^{*}$ & $50 \cdot 9 \pm 2 \cdot 9^{* *}$ \\
Motility $(\%)$ & $34 \cdot 3 \pm 0 \cdot 8$ & $37 \cdot 0 \pm 1 \cdot 3$ & $40 \cdot 1 \pm 1 \cdot 3^{* *}$ \\
$\begin{array}{l}\text { Velocity }(\mu \mathrm{m} / \mathrm{sec}) \\
\begin{array}{l}\text { Frequency of } \\
\text { rotation }(/ \mathrm{sec})\end{array}\end{array}$ & $7 \cdot 1 \pm 0 \cdot 3$ & $7 \cdot 6 \pm 0.5$ & $8 \cdot 5 \pm 0.5^{*}$ \\
$\begin{array}{l}\text { Amplitude of } \\
\text { displacement }(\mu \mathrm{m})\end{array}$ & $7 \cdot 1 \pm 0 \cdot 4$ & $7 \cdot 2 \pm 0 \cdot 4$ & $7 \cdot 2 \pm 0.3$ \\
Rolling $(\%)$ & $91.9 \pm 2 \cdot 1$ & $93 \cdot 7 \pm 1 \cdot 8$ & $95 \cdot 0 \pm 1.6$ \\
\hline
\end{tabular}

Values are mean \pm s.e.m. for 8 samples from 8 individuals.

${ }^{*} P<0.05 ;{ }^{* *} P<0.01$.

linear velocity and the frequency of sperm head rotation as observed previously (Table 4). An equivalent concentration of adenosine successfully increased the percentage of motile cells but failed to influence any of the other movement characteristics assessed (Table 6) much as had been previously observed with caffeine (Table 4).

Influence of culture medium. Since an important potential application of reagents that stimulate human sperm motility is in the practice of in-vitro fertilization therapy, the effects of 2-deoxyadenosine and caffeine in a culture medium such as Medium BWW were compared. Cryostored spermatozoa were therefore washed free of the cryostorage medium, resuspended in Medium BWW at a concentration of $10 \times 10^{6} / \mathrm{ml}$, and exposed to 2-deoxyadenosine or caffeine for $20 \mathrm{~min}$. Under these conditions only 2 -deoxyadenosine significantly increased sperm motility $(P<0.05$ : $n=8$ ). Furthermore, this effect was also observed with non-cryostored human spermatozoa incubated in Medium BWW in the presence of $2.5 \mathrm{~mm}$-2-deoxyadenosine, increasing the percentage of motile cells from $60.0 \pm 3.8 \%$ in the controls to $69.2 \pm 3.8 \%(P<0.05: n=9)$.

Influence of calcium. Since cAMP and calcium exert antagonistic actions in the regulation of sperm motility (Tash \& Means, 1983) we examined whether the failure of caffeine to enhance motility in a synthetic medium was due to the high calcium content $(1.7 \mathrm{mM})$ of Medium BWW. Crystored samples were washed free of cryostorage medium and resuspended at a concentration of 


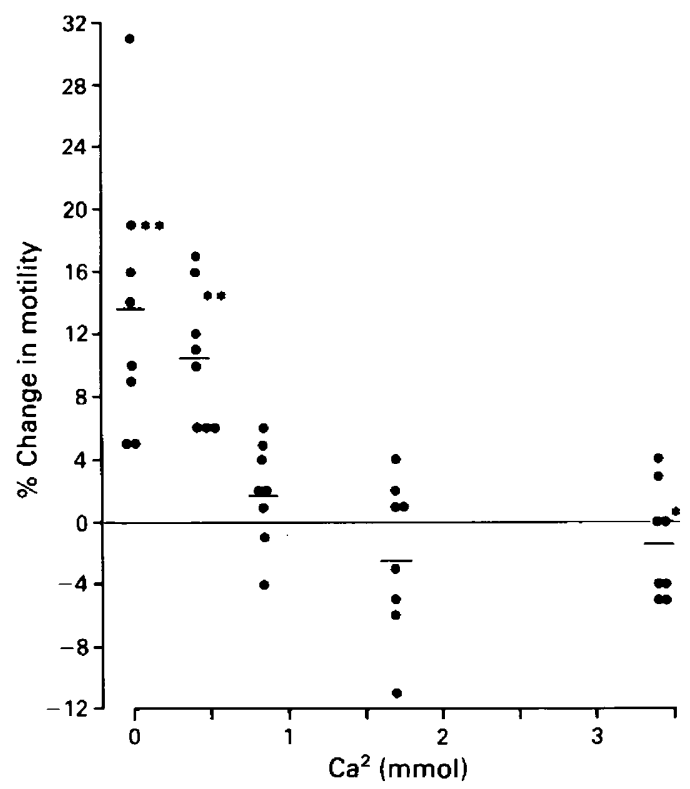

Fig. 3. Influence of extracellular calcium concentration on the ability of 5 mm-caffeine to increase the motility of cryostored human spermatozoa ( $n=8$ samples from 8 individuals). ${ }^{*} P<0.05 ;{ }^{* *} P<0.01$.

Table 7. Influence of extracellular $\mathrm{Ca}^{2+}$ on the movement characteristics of cryostored human spermatozoa exposed to $2.5 \mathrm{~mm}$-2-deoxyadenosine for $20 \mathrm{~min}$

\begin{tabular}{|c|c|c|c|c|}
\hline \multirow{2}{*}{$\begin{array}{l}\text { Movement } \\
\text { characteristics }\end{array}$} & \multicolumn{2}{|c|}{ Added $\mathrm{Ca}^{2+}$} & \multicolumn{2}{|c|}{ No added $\mathrm{Ca}^{2+}$} \\
\hline & Control & 2-Deoxyadenosine & Control & 2-Deoxyadenosine \\
\hline Motility (\%) & $41 \cdot 1 \pm 3 \cdot 2$ & $46 \cdot 0 \pm 2 \cdot 8^{*}$ & $41 \cdot 6 \pm 2 \cdot 4$ & $50 \cdot 6 \pm 3 \cdot 5^{* *}$ \\
\hline Velocity $(\mu \mathrm{m} / \mathrm{sec})$ & $39.0 \pm 0.9$ & $42 \cdot 1 \pm 1 \cdot 2^{*}$ & $39 \cdot 2 \pm 1 \cdot 4$ & $43.4 \pm 2 \cdot 8^{*}$ \\
\hline $\begin{array}{l}\text { Frequency of } \\
\text { rotation (/sec) } \\
\text { Amplitude of }\end{array}$ & $8.6 \pm 0.4$ & $10 \cdot 4 \pm 0.7^{* *}$ & $8 \cdot 8 \pm 0 \cdot 3$ & $9 \cdot 8 \pm 0 \cdot 3^{*}$ \\
\hline displacement $(\mu \mathrm{m})$ & $7 \cdot 5 \pm 0 \cdot 2$ & $7 \cdot 7 \pm 0 \cdot 3$ & $7 \cdot 8 \pm 0.3$ & $7 \cdot 8 \pm 0.3$ \\
\hline
\end{tabular}

Values are mean \pm s.e.m. for 8 samples from 8 individuals.

${ }^{*} P<0.05 ;{ }^{* *} P<0.01$.

$10 \times 10^{6} / \mathrm{ml}$ in Medium BWW modified to contain $0.0,0.425,0.85,1.7$ or $3.4 \mathrm{mM}$ calcium. These samples were then exposed to caffeine, or an equivalent volume of calcium-free Medium BWW as a control, for $20 \mathrm{~min}$ and the differences in sperm motility were assessed (Fig. 3). The results clearly revealed the interaction which exists between the ability of caffeine to increase sperm motility and the extracellular levels of free ionic calcium. In the absence of added calcium the presence of caffeine elevated the percentage of motile cells from a mean ( \pm s.e.m.) of $17.8 \pm 3.2 \%$ in the controls to $31.4 \pm 4.1 \%(P<0.01)$. A significant increase of sperm motility was also evident when the external calcium concentration was adjusted to $0.425 \mathrm{~mm}$, but at higher calcium concentrations caffeine was without effect, except in the presence of $3.4 \mathrm{~mm}$-calcium when a significant decline in sperm motility was induced $(P<0.05)$. 
In view of this interaction between extracellular calcium and the motility-enhancing properties of caffeine, a similar analysis was conducted using 2-deoxyadenosine. In this study cryostored spermatozoa were washed free of cryostorage medium and the interaction between calcium and 2-deoxyadenosine was examined. The results (Table 7) indicated that, in contrast to caffeine, 2-deoxyadenosine was able to induce the expected significant increases in percentage motility $(P<0.05)$ linear velocity and frequency of sperm head rotation $(P<0.01)$ in the presence of $1.7 \mathrm{~mm}$ extracellular calcium. Omission of the added calcium did not influence the extent to which the velocity and frequency of rotation of the spermatozoa was influenced although, under these conditions, a significantly $(P<0.02)$ greater increase in the percentage of motile cells was observed on exposure to 2-deoxyadenosine.

\section{Discussion}

The results obtained in this study indicate that 2-deoxyadenosine is one of the most potent stimulators of human sperm motility yet identified. The properties of this compound differ significantly from those exhibited by caffeine, which is the reagent in current clinical usage for the enhancement of sperm motility (Barkay et al., 1984). In contrast to caffeine, 2-deoxyadenosine is able to enhance the quality of sperm movement, particularly with respect to the linear velocity of progression, as well as the percentage of motile cells. Curiously, this property was not shared by the native compound, adenosine, which at an equivalent dose behaved in a fashion similar to caffeine in that it enhanced the proportion of motile cells without any effect on the movement characteristics of the spermatozoa. 2-Deoxyadenosine also differed from caffeine in that it was capable of sustaining the improvement of motility for a much longer period after removal of the stimulant (Table 5). This finding relates directly to the clinical potential of 2-deoxyadenosine, since if this compound is to be used to enhance motility in artificial insemination programmes, it is critical that any improvement of sperm motility is maintained during the subsequent passage of the spermatozoa through the female reproductive tract. Similarly, the prolonged duration of action of 2-deoxyadenosine will be an advantage in the practice of in-vitro fertilization therapy, since it will be possible to wash the spermatozoa free of this compound before the eggs are introduced.

A further difference between 2-deoxyadenosine and caffeine, which relates to their clinical potential in an in-vitro fertilization context, concerns their relative potencies in the presence of high levels of extracellular calcium. Caffeine was incapable of increasing the percentage of motile cells when the external calcium concentration exceeded $0.425 \mathrm{~mm}$. In contrast, 2-deoxyadenosine increased the percentage of motile cells, their velocity and the frequency of sperm head rotation in the presence of calcium levels $(1.7 \mathrm{mM})$ typical of those used for in-vitro fertilization therapy and, furthermore, these effects were observed with fresh as well as cryostored spermatozoa. Whether or not the spermatozoa stimulated by 2-deoxyadenosine are also capable of exhibiting the membrane fusion and cell recognition phenomena required to fertilize the ovum will have to be determined in future studies.

The ability of calcium to antagonize the responses to caffeine, and to a lesser extent 2-deoxyadenosine (Table 7) is in keeping with the hypothesis that cAMP and calcium exert opposing actions in the regulation of sperm motility (Tash \& Means, 1983). According to this scheme, sperm motility may be enhanced by decreasing the level of cytoplasmic calcium (Hong et al., 1984) or by increasing the intracellular level of cAMP (Aitken et al., 1983). With adenosine, 2-deoxyadenosine, caffeine and IBMX the primary biochemical effect is to increase the cAMP content of the spermatozoa. It is, however, possible that this change then leads to a secondary reduction in intracellular calcium through the phosphorylation of an outwardly directed calcium ATPase. The mechanism by which 2-deoxyadenosine elevates intracellular cAMP presumably involves an increase in adenylate cyclase activity, rather than the suppression of phosphodiesterase, since the stimulatory effects of this compound were augmented by the presence of phosphodiesterase inhibitors such as caffeine and IBMX. 
Sattin \& Rall (1970) first demonstrated that exposure to adenosine led to the augmentation of cAMP levels in brain slices as a result of an increase in adenylate cyclase activity. It is now known that adenosine can exert either stimulatory or inhibitory effects upon adenylate cyclase activity as a result of the mediation of a membrane bound receptor (Wolff et al., 1981). This receptor has been named the ' $R$ ' site because modification of the ribose moiety of adenosine, especially in positions 2 and 3, leads to a loss of activity. As a consequence, 2-deoxyadenosine has been found to be a very weak effector of such receptor-induced stimulation of adenylate cyclase in all cell types studied to date (Londos \& Wolff, 1977). The paradoxical effects of 2-deoxyadenosine observed in the present study are therefore unlikely to involve the mediation of an externally-orientated receptor similar to the conventional ' $R$ ' site. The general assumption that the adenylate cyclase complex of mammalian spermatozoa does not possess a regulatory subunit (Stengel \& Hanoune, 1984) would also be incompatible with the notion that receptor-mediated mechanisms are involved in the stimulation of adenylate cyclase activity by 2 -deoxyadenosine. Furthermore, the high doses $(2.5 \mathrm{~mm})$ of 2-deoxyadenosine required to achieve the maximum stimulation of sperm motility would again argue against receptor mediation. With other cell types, such as Leydig cells, only micromolar quantities of adenosine and its active analogues are required to stimulate adenylate cyclase activity when the ' $R$ ' site is involved (Londos \& Wolff, 1977). It is, however, possible that the high doses of adenosine and 2-deoxyadenosine required to influence human spermatozoa are due to the desensitization of the adenylate cyclase complex, which may have occurred on exposure to the high levels of prostaglandins present in human semen. Such desensitization would be expected to lead to a significant loss or inactivation of the regulatory subunit (Garrity et al., 1983) so that even if adenosine receptors were present on the sperm surface, they would not be effectively coupled to the catalytic subunit. Under such conditions high doses of ligand would be required to achieve a significant increase in adenylate cyclase activity. Alternatively the response to adenosine may have been influenced by the availability of GTP, in view of the results recently obtained for mouse spermatozoa (Stein et al., 1986).

If receptors are involved they must be quite different from the adenosine receptors described for most other cell types. Not only is the potency of 2-deoxyadenosine not typical for the ' $R$ ' site (Londos \& Wolff, 1977; Ohisalo et al., 1984) but also the enhancing effect of IBMX and caffeine contrasts with the negative influence of methyl xanthines in other adenosine responsive cells (Wolff et al., 1981).

A second possibility is that adenosine and 2-deoxyadenosine are taken into the cell and converted to cAMP via ATP. Such a mechanism has been discounted as far as the influence of adenosine on other cell types is concerned because (a) adenine does not elevate cAMP content despite the fact that it is more readily incorporated into ATP than adenosine, (b) there is no correlation between the amount of adenosine taken up and the increase in intracellular cAMP, and (c) while theophylline may block the stimulatory effects of adenosine on cAMP production it does not influence the rate of uptake of adenosine or its conversion to ATP (Wolff et al., 1981). In addition, conversion of $\left[{ }^{3} \mathrm{H}\right]$ adenosine to ATP was not observed by Brown \& Casillas (1984) in their in-vitro studies of bovine spermatozoa. We found no significant changes in the ATP content of human spermatozoa after exposure to 2-deoxyadenosine. Furthermore, the product of such a mechanism would be 2-deoxy cAMP, which is known to be less active biologically than the native cAMP molecule (Bar \& Hechter, 1969). Since 2-deoxyadenosine is, in fact, more active than adenosine in augmenting both the cAMP content of human spermatozoa and their motility, it is extremely unlikely that the biological activity of this compound depends upon its incorporation into the ATP pool and subsequent metabolism to the cyclic deoxynucleotide.

The fact that steady state levels of ATP were maintained when the spermatozoa were stimulated with 2-deoxyadenosine also indicates that the activity of this compound does not involve an increase in the availability of ATP through the allosteric inhibition of other ATP-utilizing enzymes. The normal resting level of ATP in the human spermatozoon $\left(\sim 300 \mathrm{pmol} / 10^{6}\right.$ spermatozoa $)$ is clearly adequate to sustain the fmol increases in cAMP observed with 2-deoxyadenosine. The 
maintenance of ATP levels, despite the changes in motility induced by IBMX, caffeine and 2-deoxyadenosine, also reflects the results of previous studies with human spermatozoa (Suter $e t$ al., 1979) in indicating that the genesis of ATP in such circumstances can readily cope with the increased utilization of this nucleotide by the dynein ATPase of the flagellum.

Whatever mechanism is involved it is probably not unique to the human spermatozoon since a recent report by Vijayaraghaven \& Hoskins (1986) on bovine spermatozoa has indicated that analogues substituted in the ribose ring, such as 2-chloroadenosine or 2-deoxyadenosine, stimulate sperm motility and elevate the intracellular content of cAMP. In contrast, studies of extracts of human (Hyne \& Lopata, 1982) and bovine (Brown \& Casillas, 1984) spermatozoa have revealed that high doses of adenosine inhibit adenylate cyclase activity in a manner typical of P-site mediation. Clearly the relationships between adenylate cyclase, cAMP and sperm motility are complex and further studies will be needed to develop a coherent framework within which these apparently contradictory findings can be reconciled.

We thank Ms Jane Clarkson, Mr Martin Hulme and Mr David Richardson for expert assistance in the realisation of these studies; Poli Italiana for financial support; and Dr Rodney Kelly for helpful suggestions.

\section{References}

Aitken, R.J., Best, F.S.M., Richardson, D.W., Djahanbakhch, O. \& Lees, M.M. (1982) The correlates of fertilizing capacity in normal fertile men. Fert. Steril. 38, 68-76.

Aitken, R.J., Best, F.S.M., Richardson, D.W., Schats, R. \& Simm, G. (1983) Influence of caffeine on movement characteristics, fertilizing capacity and ability to penetrate cervical mucus of human spermatozoa. $J$. Reprod. Fert. 67, 19-27.

Aitken, R.J., Ross, A., Hargreave, T., Richardson, D. \& Best, F. (1984) Analysis of human sperm function following exposure to the ionophore A23187. J. Androl. 5, 321-329.

Bär, H-S. \& Hechter, O. (1969) Substrate specificity of adenyl cyclase from rat fat cell ghosts. Biochim. Biophys. Acta 192, 141-144.

Barkay, J., Bartoov, B., Ben-Ezra, S., Langsham, J., Feldman, E., Gordon, S. \& Zuckerman, H. (1984) The influence of in vitro caffeine treatment on human sperm morphology and fertilizing capacity. Fert. Steril. 41, 913-918.

Biggers, J.D., Whitten, W.K. \& Whittingham, D.G. (1971) The culture of mouse embryos in vitro. In Methods in Mammalian Embryology, pp. 86-116. Ed. J. C. Daniel, Jr. Freeman, San Francisco.

Brown, M.A. \& Casillas, E.R. (1984) Bovine sperm adenylate cyclase. $J$. Androl. 5, 361-368.

Fraser, L.R. (1979) Accelerated mouse sperm penetration in vitro in the presence of caffeine. J. Reprod. Fert. 57, 377-384.

Fraser, L.R. (1979) Accelerated mouse sperm penetration in vitro in the presence of caffeine. J. Reprod. Fert. 57, 377-384.

Garbers, D.L. \& Kopf, G.S. (1980) The regulation of spermatozoa by calcium and cyclic nucleotides. $A d v$. Cyclic Nucl. Res. 13, 251-306.
Garrity, M.J., Andreasen, T.J., Storm, D.R. \& Robertson, R.P. (1983) Prostaglandin E-induced heterologous desensitization of hepatic adenylate cyclase. $J$. biol. Chem. 258, 8692-8697.

Harper, J.K. \& Brooker, G. (1975) Femtomole sensitive radioimmunoassay for cyclic AMP and cyclic GMP after $2^{\prime}, 0$ acetylation by acetic anhydride in aqueous solution. J. Cyclic Nucl. Res. 1, 207-218.

Hong, C.Y., Chiang, B.N., Ku, J. \& Wei, Y.H. (1984) Calcium chelators stimulate sperm motility in ejaculated human semen. Lancet, February 25, 460-461.

Hoskins, D.D., Hall, M.L. \& Münsterman, D. (1975) Induction of motility in immature bovine spermatozoa by cyclic AMP phosphodiesterase inhibitors and seminal plasma. Biol. Reprod. 13, 168-176.

Hyne, R.V. \& Garbers, D.L. (1979) Calcium-dependent increase in adenosine $3^{\prime}, 5^{\prime}$-monophosphate and induction of the acrosome reaction in guinea pig spermatozoa. Proc. natn. Acad. Sci. U.S.A. 76, 5699-5703.

Hyne, R.V. \& Lopata, A. (1982) Calcium and adenosine affect human sperm adenylate cyclase activity. Gamete Res. 6, 81-89.

Jackson, M.C.N. \& Richardson, D.W. (1977) The use of fresh and frozen semen in human artificial insemination. J. biosoc. Sci. 9, 251-262.

Klausner, R.D., Fishmen, M.C. \& Karnovsky, M.J. (1979) Ionophore A23187 disrupts membrane structure by modifying protein-lipid interactions. Nature, Lond. 281, 82-83.

Kopf, G.S. \& Vacquier, V.D. (1985) Characterisation of a calcium-modulated adenylate cyclase from abalone spermatozoa. Biol. Reprod. 33, $1094-1104$.

Londos, C. \& Wolf, J. (1977) Two distinct adenosinesensitive sites on adenylate cyclase. Proc. natn. Acad. Sci. U.S.A. 74, 5482-5486. 
Makler, A., Makler, E., Itzkovitz, J. \& Brandes, J.M. (1980) Factors affecting sperm motility. IV Incubation of human semen with caffeine, kallikrein, and other metabolically active compounds. Fert. Steril. 33, 624-630.

McOsker, C.C., Weiland, G.A. \& Zilversmit, D.B. (1983) Inhibition of hormone-stimulated adenylate cyclase activity after altering turkey erythrocyte phospholipid composition with a nonspecific lipid transfer protein. J. biol. Chem. 258, 13017-13026.

Ohisalo, J.J., Ranta, S. \& Huhtaniemi, I.T. (1984) Inhibition of adenosine $3^{\prime}, 5^{\prime}$-monophosphate accumulation and lipolysis by adenosine analogs in human subcutaneous adipocytes. J. clin. Endocr. Metab. 58, 32-35.

Overstreet, J.W., Katz, D.F., Hanson, F.W. \& Fonseca, J.R. (1979) A simple inexpensive method for objective assessment of human sperm movement characteristics. Fert. Steril. 31, 162-172.

Pariset, C.C., Roussel, C., Weinman, S.J. \& Demaille, J.G. (1983) Calmodulin intracellular concentration and cAMP-dependent protein kinase activity in human sperm samples in relation to sperm morphology and motility. Gamete Res. 8, 171-182.

Pariset, C.C., Feinberg, J.M.F., Dacheux, J.L. \& Weinham, S.J. (1985) Changes in calmodulin level and cAMP-dependent protein kinase activity during epididymal maturation of ram spermatozoa. $J$. Reprod. Fert. 74, 105-112.

Sattin, A. \& Rall, T.W. (1970) The effect of adenosine and adenine nucleotides on the cyclic adenosine $3^{\prime}, 5^{\prime}$ phosphate content of guinea pig cerebral cortex slices. Molec. Pharmacol. 6, 13-23.
Stein, D.M. \& Fraser, L.R. (1984) Cyclic nucleotide metabolism in mouse epididymal spermatozoa during capacitation in vitro. Gamete Res. 10, 283-299.

Stein, D.M., Fraser, L.R. \& Monks, N.J. (1986) Adenosine and Gpp (NH)P modulate mouse sperm adenylate cyclase. Gamete. Res. 13, 151-158.

Steiner, A.L., Parker, C.W. \& Kipnis, D.M. (1972) Radioimmunoassay for the measurement of adenosine $3^{\prime}, 5^{\prime}$-cyclic phosphate. J. biol. Chem. 247, 1106-1113.

Stengel, D. \& Hanoune, J. (1984) The sperm adenylate cyclase. Ann. N.Y. Acad. Sci. 438, 18-28.

Suter, D., Chow, P.Y.W. \& Martin, I.C.A. (1979) Maintenance of motility in human spermatozoa by energy derived through oxidative phosphorylation and addition of albumin. Biol. Reprod. 20, 505-510.

Tash, J.S. \& Means, A.R. (1983) Cyclic adenosine $3^{\prime}, 5^{\prime}$ monophosphate, calcium and protein phosphorylation in flagellar motility. Biol. Reprod. 28, 75-104.

Vijayaraghavan, S. \& Hoskins, D.D. (1986) Regulation of bovine sperm motility and cyclic adenosine $3^{\prime}, 5^{\prime}$ monophosphate by adenosine and its analogues. Biol. Reprod. 34, 468-477.

Vihayaraghavan, S., Critchlow, L.M. \& Hoskins, D.D. (1985) Evidence for a role for cellular alkalinization in the cyclic adenosine $3^{\prime}, 5^{\prime}$-monophosphatemediated initiation of motility in bovine caput spermatozoa. Biol. Reprod. 32, 489-500.

Wolff, J., Londos, C. \& Cooper, D.M.F. (1981) Adenosine receptors and the regulation of adenylate cyclase. Adv. Cyclic Nucl. Res. 4, 199-214. 